\title{
Elimination of Cancer Health Disparities through the Acceleration of HPV Vaccines and Vaccinations: A Simplified Version of the President's Cancer Panel Report on HPV Vaccinations
}

Eva McGhee*, Hill Harper, Adaku Ume, Melanie Baker, Cheick Diarra, John Uyanne, Sebhat Afework, Keosha Partlow, Lucy Tran, Judith Okoro, Anh Doan, Karen Tate, Mechelle Rouse, Meidrah Tyler, Kamilah Evans, Tonya Sanchez, Ishmum Hasan, Enijah Smith-Joe, Jasmine Maniti, Liliana Zarate, Camille King, Antoinette Alugbue, Chiamaka Opara, Bileko Wissa, Joanne Maniti and Roland Pattillo

Department of Internal Medicine, Charles Drew University of Medicine and Science, Los Angeles, USA

*Corresponding author: Eva McGhee, Department of Internal Medicine, Charles Drew University of Medicine and Science, 1731 East $120^{\text {th }}$ Street, Los Angeles, CA-90059, USA, Tel: 323-563-9382; E-mail: evamcghee@cdrewu.edu

Received date: May 02, 2017; Accepted date: May 25, 2017; Published date: May 29, 2017

Copyright: $\odot 2017$ McGhee E, et al. This is an open-access article distributed under the terms of the Creative Commons Attribution License, which permits unrestricted use, distribution, and reproduction in any medium, provided the original author and source are credited.

\begin{abstract}
The human papillomavirus (HPV) is a major public health concern affecting both females and males. HPV is associated with cervical, anal, head and neck cancers. About $99 \%$ of all cervical cancers are related to HPV. HPV vaccines, Gardasil, Cervarix, and Gardasil 9 are used in the primary prevention of HPV related cancers. Gardasil and Gardasil 9 are available for use in both females and males ages 9 to 26, while Cervarix is available for females ages 9 to 25. Gardasil 9 was approved by the FDA for prevention against additional HPV types. Despite the availability of this preventative measure against cervical cancer, the rate of HPV vaccination in the United States remains lower than that of other industrialized nations. The purpose of this study is to elucidate mechanisms to help increase the HPV vaccination rate by using education as a tool; by simplifying the president report so that lay person can understand the information presented in the report. Through the quantitative examination of the data from the states with the lowest and highest vaccination rates, using SPSS statistical analysis; we analyzed several factors involved with the low uptake of the vaccines. The results collected show that socioeconomic status, misconceptions about HPV, and misconceptions about the safety of the vaccines were identified as possible obstacles to the effective uptake of HPV vaccinations. The proposals made by the President's Cancer Panel to accelerate the uptake of vaccines include, increasing coverage of the vaccines through government-sponsored programs, and the Affordable Care Act; increasing accessibility to vaccines through pharmacies, schools, and clinics; and disseminating more information on HPV to healthcare providers, parents, caregivers, and patients. Allowing greater accessibility to the vaccines for all populations regardless of income, education, and eliminating misconceptions of the vaccines would play a significant role in eliminating cancer.
\end{abstract}

Keywords: Cancer; HPV vaccine; Gardasil; Cervarix; Gardasil-9

\section{Introduction}

The Human papillomavirus (HPV) infection is a major public health concern. Approximately 80 million or one in four people are infected with this virus in the United States [1]. HPV infections cause nearly 26,000 new cases of cancer in the U.S. and more than 600,000 cases worldwide each year [2]. Despite the availability of HPV vaccines that serve as primary prevention against these cancers, there is evidence that show low rate of uptake as low as $12 \%$ in some states in US and the highest uptake in the US being almost $57.7 \%$ (Figure 1 and Table 1) also shown in Figure 1 is the cervical cancer incidence rates by states [3]. This finding alarmed the President's Cancer Panel, and became the focus of the Panel's annual 2012-2013 report. In the report, the panel claims that HPV vaccine uptake lags behind that of other adolescent vaccines, leaving millions of adolescents vulnerable to infection with the cancer-causing virus [3]. The panel lists four goals in the report that if met, would ultimately lead to higher rates of vaccine uptake and significantly lower rates of cervical cancer and other cancers in the future. Although the Panel's charge is focused on the U.S. National Cancer Program, the Panel recognizes the role of the United States in supporting cancer control efforts in other parts of the world. The Cancer Panel hopes that if HPV vaccination is made a public health priority by many different organizations, HPV and it's associated diseases would be eradicated $[3,4]$.

\section{HPV is a sexually transmitted infection that is linked to the occurrence of various cancers}

The Human Papillomavirus (HPV) consists of a group of over 200 types of double-stranded DNA viruses belonging to the Papillomaviridae family. Genital human papillomavirus (HPV) is the most common sexually transmitted infection in the United States. More than 40 types of HPV are typically transmitted through sexual contact, and infect the anogential region (anus and genitals) [4]. Most HPV infections do not present definite or readily observable symptoms; however, some infections progress to develop benign papillomas (warts). HPV is known to infect keratinocytes in the skin and mucosal membranes and can cause abnormal growth of tissue, leading to precancerous lesions and invasive cancers of the cervix, vulva, vagina, penis, oropharynx, or anus [5]. "High-risk HPV infection" is the cause of nearly all cases of cervical cancer. An estimated 14 million people are newly infected with HPV each year; approximately half of the new HPV infections occur among people aged 15-24 years this data represents the US and foreign countries; HPV accounts for considerable morbidity and economic burden in the US population [6]. 
Citation: McGhee E, Harper H, Ume A, Baker M, Diarra C, et al. (2017) Elimination of Cancer Health Disparities through the Acceleration of HPV Vaccines and Vaccinations: A Simplified Version of the President's Cancer Panel Report on HPV Vaccinations. J Vaccines Vaccin 8: 361. doi:10.4172/2157-7560.1000361

Page 2 of 7

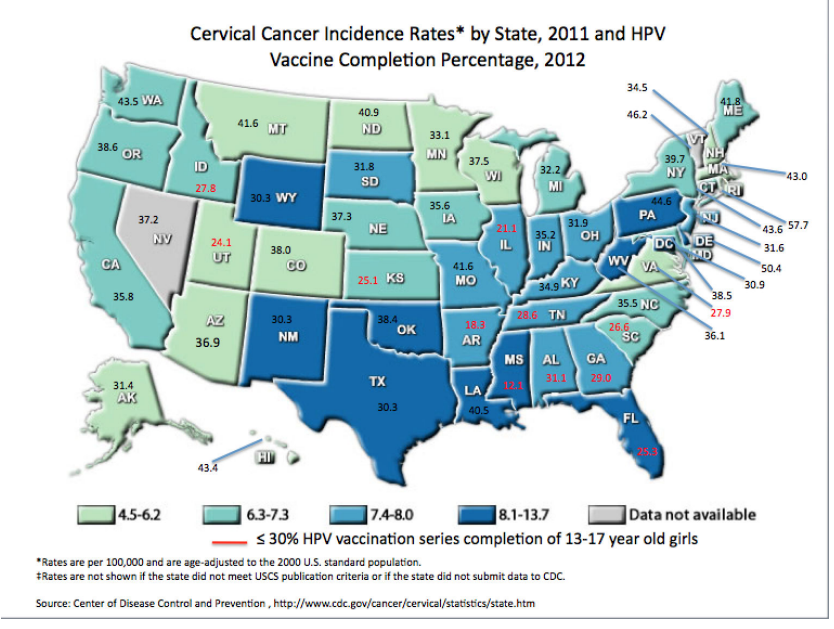

Figure 1: Percentage of 13 to 17 Year-Old Girls Completing HPV Vaccines Series, and Cervical Cancer Incidence Rates by State, and HPV Vaccine Completion Percentage Map. HPV vaccine completion percentages are displayed in numerical value to their corresponding states. The colors represent the cervical cancer incidence rate bracket each state falls in. States with less than or equal to 30 percent vaccine completion rates are highlighted in red.

Percentage of 13-to 17-Year-Old Girls Completing HPV Vaccine Series, U.S., 2012

\begin{tabular}{|c|c|c|c|c|c|}
\hline Range & State & Percent & Range & State & Percent \\
\hline \multirow[t]{2}{*}{$\geq 50 \%$} & Rhode Island & 57.7 & & Kentucky & 34.9 \\
\hline & Delaware & 50.4 & & Missouri & 34.5 \\
\hline \multirow[t]{10}{*}{$40-49 \%$} & Vermont & 46.2 & & $\begin{array}{l}\text { New } \\
\text { Hampshire }\end{array}$ & 34.5 \\
\hline & Pennsylvania & 44.6 & & Minnesota & 33.1 \\
\hline & Hawaii & 43.4 & & Michigan & 32.2 \\
\hline & Connecticut & 43.6 & & Ohio & 31.9 \\
\hline & Washington & 43.5 & & South Dakota & 31.8 \\
\hline & Massachusetts & 43 & & New Jersey & 31.6 \\
\hline & Maine & 41.8 & & Alaska & 31.4 \\
\hline & Montana & 41.6 & & Alabama & 31.1 \\
\hline & North Dakota & 40.9 & & Maryland & 30.9 \\
\hline & Louisiana & 40.5 & & New Mexico & 30.3 \\
\hline \multirow[t]{5}{*}{$30-39 \%$} & New York & 39.7 & & Texas & 30.3 \\
\hline & Oregon & 38.6 & & Wyoming & 30.3 \\
\hline & $\begin{array}{ll}\text { District } & \text { of } \\
\text { Columbia } & \end{array}$ & 38.5 & $\leq 29 \%$ & Georgia & 29 \\
\hline & Oklahoma & 38.4 & & Tennessee & 28.6 \\
\hline & Colorado & 38 & & Virginia & 27.9 \\
\hline
\end{tabular}

\begin{tabular}{|l|l|l|l|l|l|}
\hline & Wisconsin & 37.5 & & Idaho & 27.8 \\
\hline & Nebraska & 37.3 & & $\begin{array}{l}\text { South } \\
\text { Carolina }\end{array}$ & 26.6 \\
\hline & Nevada & 37.2 & & Florida & 25.3 \\
\hline & Arizona & 36.9 & & Kansas & 25.1 \\
\hline & West Virginia & 36.1 & & Utah & 24.1 \\
\hline & North Carolina & 35.5 & & Illinois & 21.1 \\
\hline & California & 35.8 & & Arkansas & 18.3 \\
\hline & lowa & 35.6 & & Mississippi & 12.1 \\
\hline & Indiana & 35.2 & & & \\
\hline
\end{tabular}

Table 1: Percentages of 13 to 17 Year-Old Girls Completing HPV Vaccine Series. The Center for Disease Control (CDC) estimates that efforts to increase the current HPV vaccination rates to around $80 \%$ would prevent an additional 53,000 future cervical cancer cases among 12 -year-old girls or younger. Table 3, also indicate that any number under $30 \%$ is considered low uptake.

Annual costs of cervical cancer screening and treatment of HPVassociated conditions have been estimated at $\$ 8$ billion U.S. dollars. In 2009, approximately 30,000 HPV-associated cancers were reported in the United States, with $39 \%$ prevalence in males Table 2 . As previously mentioned, over $200 \mathrm{HPV}$ types have been identified, with HPV types 16 and 18 causing approximately $70 \%$ (400,000 reported cases) of cervical cancers globally $[3,7]$.

\begin{tabular}{|c|c|c|c|c|c|}
\hline Cancer Site & $\begin{array}{l}\text { Average } \\
\text { \# Cancer } \\
\text { per Year } \\
\text { at Site (a) }\end{array}$ & $\begin{array}{l}\text { Percent } \\
\text { Probably } \\
\text { Caused } \\
\text { by HPV } \\
\text { (a) }\end{array}$ & $\begin{array}{l}\text { Number } \\
\text { Probably } \\
\text { Caused } \\
\text { by HPV } \\
\text { (a) }\end{array}$ & $\begin{array}{l}\text { Percent } \\
\text { HPV } \\
\text { Cancers } \\
\text { Probably } \\
\text { Caused by } \\
\text { HPV } 16 \text { or } \\
18 \text { (b) }\end{array}$ & $\begin{array}{l}\text { Number of } \\
\text { Cancers } \\
\text { per Year } \\
\text { Probably } \\
\text { Caused by } \\
\text { HPV } 16 \text { or } \\
18\end{array}$ \\
\hline Anus & 4,767 & 93 & 4,500 & 93 & 4,200 \\
\hline Cervix & 11,967 & 96 & 11,500 & 76 & 8,700 \\
\hline Oropharynx & 11,726 & 63 & 7,400 & 95 & 7,000 \\
\hline Penis & 1,046 & 36 & 400 & 87 & 300 \\
\hline Vagina & 729 & 64 & 500 & 88 & 400 \\
\hline Vulva & 3,136 & 51 & 1,600 & 86 & 1,400 \\
\hline Total & 33,371 & & 25,900 & & 22,000 \\
\hline
\end{tabular}

Table 2: U.S. Cancers Attributed to HPV. Adapted from The President's Cancer Panel Report. The table demonstrates the percentage of cancers in the United States attributed to HPV. Centers for Disease Control and Prevention. Human papillomavirus-associated cancers - United States, 2004-2008. (b) Gillison ML, Chaturevedi AK, Lowy DR. HPV prophylactic vaccines and the potential of noncervical cancers in both men and women. Cancer. 2008;113 (10 Suppl):3036-46 [6]. 
Citation: McGhee E, Harper H, Ume A, Baker M, Diarra C, et al. (2017) Elimination of Cancer Health Disparities through the Acceleration of HPV Vaccines and Vaccinations: A Simplified Version of the President's Cancer Panel Report on HPV Vaccinations. J Vaccines Vaccin 8: 361. doi: $10.4172 / 2157-7560.1000361$

Page 3 of 7

\section{HPV vaccines prevent the occurrence of cervical cancer and other HPV-associated health outcomes}

Three HPV vaccines are licensed in the United States for prevention of specific HPV types and HPV-associated outcomes. Gardasil (Merck and Co., Inc.), a quadrivalent HPV vaccine, was licensed by the Food and Drug Administration (FDA) in 2006 for use in females aged 9-26 years as prevention of cervical cancer and its precursors, vulvar and vaginal cancer precursors, and anogential warts caused by HPV types $6,11,16$ and 18 [3]. Three years later, the FDA licensed the bivalent vaccine, Cevarix (GlaxoSmithKline) for use in females aged 9-25 years for prevention of cervical cancer and its precursors caused by HPV types 16 and 18. The FDA approved Gardasil $9^{\circ}$ (Merck and Co., Inc.), a 9-valent HPV vaccine for prevention against HPV types 6, 11, 16, 18, 31, 33, 45, 52, and 58 in December 2014 Table 3 [8]. Gardasil 9 is a vaccine approved for use in females in the same age range recommended by the quadrivalent Gardasil vaccine and is also recommended for use in male's ages 9 through 15 . The 9-Valent vaccine (Gardasil 9) has the potential to prevent approximately $90 \%$ of cervical, vulvar, vaginal and anal cancers. Both vaccines are administered as a 3-dose series over 6 months. The 9-valent HPV Vaccine was introduced in 2014 as one of his newest forms of cancer prevention among males and females between the ages of 9 to 26 years $[9,10]$. Researchers of this vaccine tested the efficacy and immunogenicity among women age $16-26$ in a randomized, international, double-blinded test. Researchers ultimately found that this vaccine offered the potential to increase overall prevention of cervical cancer from $70 \%$ to $90 \%$. Though there were limitations within the study, the FDA felt that the results of the study were significant enough to release the drug to the public [11].

\begin{tabular}{|c|c|c|c|}
\hline $\begin{array}{l}\text { HPV TypesHPV Types } \\
\text { Manufacturer } \\
\text { Initial U.S Licensing }\end{array}$ & $\begin{array}{l}\text { Gardasil } \\
6,11,16,18 \\
\text { Merck\& Co. } \\
2006\end{array}$ & $\begin{array}{l}\text { Cervarix } \\
16,18 \\
\text { GlaxoSmithKline } \\
2009\end{array}$ & $\begin{array}{l}\text { Gardasil } 9 \\
6,11,16,18,31,33,45,52,58 \\
\text { Merck. } \\
2014\end{array}$ \\
\hline Approved for prevention of & $\begin{array}{l}\text { Cervical cancer and precancers, vulvar } \\
\text { cancer and precancers, vaginal cancer } \\
\text { and precancers, Anal cancer and } \\
\text { precancers, genital warts }\end{array}$ & Cervical cancer and precancers & $\begin{array}{l}\text { Cervical cancer and precancers, vulvar cancer } \\
\text { and precancers, vagonal cancer and } \\
\text { precancers, anal cancer and precancers }\end{array}$ \\
\hline Approved for use in & $\begin{array}{l}\text { Females ( } 9 \text { to } 26 \text { years old) } \\
\text { Males ( } 9 \text { to } 26 \text { years old) }\end{array}$ & Females ( 9 to 25 years old) & $\begin{array}{l}\text { Females ( } 9 \text { to } 26 \text { years old) } \\
\text { Males ( } 9 \text { to } 15 \text { years old) }\end{array}$ \\
\hline
\end{tabular}

Table 3: HPV vaccines currently administered against cervical cancer causing HPV types. Gardasil, Cevarix and recently FDA approved vaccine Gardasil 9 could prevent the majority of cervical cancers if used optimally [6].

HPV vaccines work by stimulating the body to produce antibodies that recognize and bind to the HPV virus, preventing it from infecting cells. The current HPV vaccines are made up of virus-like particles (VLPs) that have been formed from HPV surface components using recombinant DNA technology [12]. Because the VLPs lack viral DNA, they are not infectious. However, since they contain the same surface components as the actual HPV virus, the antibodies produced from the vaccine will recognize the natural virus. This makes the vaccines highly effective.

\section{HPV vaccine uptake has not kept pace with that of other adolescent vaccines over the years}

Today, there are three effective vaccines that prevent infection by the two most prevalent cancer-causing HPV types. However, in 2012, 33\% of adolescent females and $7 \%$ of adolescent males across the U.S. completed the three-dose series [13]. These low vaccination rates reveal countless missed opportunities to prevent cancers and other HPV-associated health outcomes. HPV vaccines are underused not only in the U.S., but also around the world. The President's Cancer Panel's Annual Report (2012-2013) addresses this concern about the HPV vaccine under-use which poses a serious threat to progress against cancer and notes specific goals in order to increase vaccine uptake. These goals being to reduce missed clinical opportunities, increase acceptance of disease, maximize access to the vaccine and promote global vaccination uptake. A 2010 study on HPV adherence shown that very few females receive their second and third vaccinations early, many of them receive it late. It was also determined that there were lower completion rates among African American patients compared to their white counterparts $[3,14]$.

\section{President Obama's Cancer Panel addresses concerns over vaccine underuse in 2012-2013 report}

In the United States, rates of cervical infection with HPV types covered by the vaccines fell by more than $50 \%$ among girls $14-19$ years in the four years following vaccine introduction. The decline was even more dramatic across the globe, as the prevalence of HPV infections covered by the vaccine among females under the age of 21 plummeting by as much as $90 \%$. Although 56 million vaccine doses have been administered in the United States as of early 2013, The U.S. Advisory Committee on Immunization Practices (ACIP) and the President's Cancer Panel called for "urgency for action" in accelerating the HPV vaccine uptake in the 2012-2013 annual report to President Obama $[3,15]$. The panel's report urges for the safety and efficacy of these vaccines through "excellent safety profiles" similar to those of other licensed adolescent vaccines, citing no serious safety concerns. The U.S. ACIP recommends routine vaccination of females ages 11 or 12 years with the three doses of either Cervarix ${ }^{\circ}$ or Gardasil. The vaccination series can be started beginning at age 9 years. Vaccination is recommended for female's ages 13-26 who have not been vaccinated previously or who have not completed the three-dose series.

In 2007, the first full year after Gardasil was approved in the U.S., about $25 \%$ of 13 to 17 years old girls received at least one HPV vaccine dose, with this rate being similar to the proportion that received other adolescent vaccines during the first year they were recommended. In 
Citation: McGhee E, Harper H, Ume A, Baker M, Diarra C, et al. (2017) Elimination of Cancer Health Disparities through the Acceleration of HPV Vaccines and Vaccinations: A Simplified Version of the President's Cancer Panel Report on HPV Vaccinations. J Vaccines Vaccin 8: 361. doi: $10.4172 / 2157-7560.1000361$

Page 4 of 7

2012, 53.8\% of 13 to 17 -year-old girls had received the first HPV dose, with $33.4 \%$ completing all three recommended doses.

The panel's report pleads for HPV vaccine uptake to be a public health priority and lists a plan of action by recruiting for help from the government, providers, parents and adolescents. The panel recommends the following four goals to help increase uptake of HPV vaccines in the United States (and globally) with hopes of having ageeligible adolescents fully vaccinated (completion of the three-dose vaccine).

\section{Goal 1: Reduce Missed Clinical Opportunities to Recommend and Administer HPV Vaccines}

The CDC cites in a recent report that missed clinical opportunities are the most important reason why vaccine uptake remains low in the United States. Many vaccine-eligible adolescents do not receive HPV vaccines during visits with their healthcare providers. The report states that many times, adolescents received other recommended vaccines yet did not receive the HPV vaccine. Factors contributing to providers' hesitancy include:

Limited understanding of HPV-associated diseases and benefits of HPV vaccination, particularly for males

- Concerns about safety

- Concerns about inadequate reimbursement for vaccines

- Personal attitudes and beliefs

- Discomfort talking to parents and adolescents about a topic related to sexual behavior

- Concerns about parental resistance

- Preference for vaccinating older $v s$. younger adolescents

- Lack of time or incentives to educate parents and patients about HPV and HPV vaccines

- Lack of systems to remind providers to offer vaccines to ageeligible patients

Source: Rimer BK, Harper H, White ON. Accelerating HPV vaccine uptake: Urgency for Action to Prevent Cancer: A report to the President of the United States from the President's Cancer Panel.

To address provider concerns, the Panel listed strategies to increase provider education on the safety and efficacy of the vaccines. Additionally, the Panel recommends the CDC to develop, test, disseminate, and evaluate the impact of integrated, comprehensive communication strategies for physicians and other health care professionals. In order to lead this effort, the Panel also suggests that more governmental funding be allocated to this cause. As the panel campaigns for the increase in demand of the HPV vaccine, they also recommend that healthcare payers be reimbursed adequately for HPV vaccination storage, administration and services.

The panel solicits the help of healthcare organizations and practices emphasizing the use of electronic health records (EHRs) and immunization information systems (IIS) to avoid missed opportunities for the HPV vaccination. This increase in funding would cover the cost of increasing vaccine uptake in adolescent males and having this information published in the Healthcare Effectiveness Data and Information Sheet (HEDIS) [16]. The HEDIS report is an important tool used in measuring the performance of health plans. Currently, HEDIS does not include information on vaccine uptake in males.

J Vaccines Vaccin, an open access journal

\section{HPV Vaccination in Males}

HPV has largely been associated with a disease ridden only to women. Recent findings have suggested that HPV may also lead to HPV-related cancers and genital warts in men [17]. These include cancers of the upper aero-digestive tract and the anogenital tract, and their precursor lesions. HPV related upper aero-digestive cancers include cancer of the oral cavity, oropharynx, hypo larynx, and larynx. HPV type 16 has also been linked to the development of penile, anal, head and neck cancers [18]. Evidence from a recent study in patients with penile carcinoma $(n=49)$ demonstrated that HPV was present in $77.5 \%$ of cases; specifically HPV types 16 and 18 , which were present in $84.2 \%$ and $10.5 \%$ of cases, respectively [19]. Other cancers such as HPV-positive oropharyngeal cancer, has increased significantly in incidence over the recent decades among men. Annual numbers of overall oropharyngeal cancer cases now surpass that of cervical cancers. Unfortunately, most HPV-driven oropharyngeal cancer cases are diagnosed at an advance clinical stage (III-IV).

Increasing vaccination uptake in males is a key objective in reducing missed clinical opportunities. Given that HPV infection can result in genital warts, precancerous and cancerous lesions in both males and females, the cancer panel's key objective in increasing vaccine uptake is increasing vaccine utilization in adolescent males, where vaccination rates remain the lowest [20]. Despite our increasing knowledge about HPV and the benefits of HPV vaccinations, its prevalence among men remains a challenge to healthcare systems around the world. Since there is no current test to detect HPV in men, the numbers of infected men is underestimated. Furthermore, most men who have a genital HPV infection may not have any signs or symptoms. To date, there is no cure for HPV; therefore, our best defense is through prevention by way of HPV education and vaccination among men. According to a national health interview survey, HPV vaccination initiation among men aged $18-26$ years was $1.1 \%$. According to this same survey, $51.8 \%$ of men aged 18-26 years had never heard of HPV, and $34.8 \%$ of men aged 18-26 years had never heard of the HPV vaccine [21]. In addition, the Healthy People initiative provides science-based, 10-year national objectives for improving the health of the U.S. population. Current Healthy People 2020 objectives include increasing HPV vaccine completion rates for females ages 13 to 15 years to 80 percent. The panel suggests that Healthy People 2020 objectives should be updated to include an HPV vaccination goal for males equivalent to that for females.

\section{Goal 2: Increase Parents', Caregivers', and Adolescents' Acceptance of HPV Vaccines}

Parents or other caregivers' attitudes towards vaccines heavily influences whether their children receive them. One study found that parents were more likely to refuse HPV vaccines more than other recommended vaccines for a myriad of reasons. These reasons include, but are not limited to, vaccines not being needed for males, son or daughter not being sexually active, and safety concerns. Surveyed pediatricians and family practice physicians reported that parents of young adolescents get upset when vaccinations against sexually transmitted infections are suggested for their children. Some parents express their concerns that HPV vaccinations promote engaging in sexual activity. To alleviate parental concerns and ease the conversation between providers and parents about HPV vaccine uptake, the panel suggests that the CDC implement communication strategies that focus on messages and modes of delivery that are "sensitive to cultural, literacy/health literacy, and language differences of target populations". 
Citation: McGhee E, Harper H, Ume A, Baker M, Diarra C, et al. (2017) Elimination of Cancer Health Disparities through the Acceleration of HPV Vaccines and Vaccinations: A Simplified Version of the President's Cancer Panel Report on HPV Vaccinations. J Vaccines Vaccin 8: 361. doi: $10.4172 / 2157-7560.1000361$

Page 5 of 7

The panel suggests that providers "resonate emotionally" with parents and caregivers, framing HPV vaccines as mechanisms of cancer prevention, while highlighting the safety and efficacy of these vaccines. They also suggest the importance of vaccinating both males and females as part of the adolescent vaccine initiative, while stressing the importance of initiation and completion of the vaccination series. In order to change the perception of HPV vaccines amongst parents and caregivers, the panel plans to utilize websites, blogs, social and print media with recruitment of vaccination proponents who are influential to target audiences to increase vaccine uptake. These efforts are believed to ease physician efforts to convey strong recommendations regarding HPV vaccination.

\section{Goal 3: Maximize Access to HPV Vaccination Services}

Although the American Academy of Pediatrics and American Academy of Family Physicians prefer that all adolescents receive primary care, including vaccinations through primary care physicians, the panel recommends increasing the range of venues to include more providers for HPV vaccination. U.S. Schools and pharmacies are among the top two venues suggested in the proposed expansion plan. Survey results indicate that HPV vaccination in alternative settings may prove effective in increasing vaccine uptake in adolescent males, as many of the males surveyed had not had any recent health care visits.

Reports claim that schools can educate adolescents and parents on the importance of vaccination and can even provide a clinical environment to administer HPV vaccines. School-based vaccination programs have been reported to be successful in countries like Australia, the United Kingdom and Canada, which the panel suggests for adoption in the U.S. Pharmacies are highly accessible to most people in the United States, with over 275,000 pharmacists operating out of over 60,000 pharmacies nationwide. During the 2012-2013 flu season, pharmacists were influential in administering the flu vaccination as they accounted for 20 percent of vaccine received. The panel recommends that pharmacists be allowed to administer vaccines to adolescents, as many of them are prohibited from administering HPV vaccines, especially to young adolescents.

\section{Goal 4: Promote Global HPV Vaccine Uptake}

HPV-associated cancers affect various populations worldwide, with cervical cancer being the most prevalent. The disparities in cervical cancer rates in countries such as Africa (15 times higher) vs. the U.S. may be attributed to the lack of cervical cancer education and screening programs. With data consistently showing the relationship between HPV types 16 and 18 and the progression of cervical cancer, the panel strongly recommends that vaccine uptake increase globally. In a global perspective, high-resourced areas such as Australia, the United Kingdom and Canada have astonishingly different health care systems than that of the United States and have done well in implementing HPV vaccination programs with rates as high as 50-85\%.

Efforts to expand HPV vaccination to low- and middle-income countries (LMICs) are recognized through the efforts of the GAVI Alliance (formerly known as the Global Alliance for Vaccines and Immunization) and the Pan American Health Organization (PAHO) Revolving Fund. In 2013, GAVI launched a program that provides HPV vaccines to more than 180,000 girls in eight countries. GAVI is also helping countries like Rwanda establish a HPV vaccination program (i.e. Medical staff, supplies, distribution systems, storage management). They have also partnered with the Islamic Development Bank (IDB) to catalyze the implementation of many vaccines (including HPV vaccinations) in IDB member countries. The panel suggests that the U.S. continue to support GAVI and other world health organizations with a heavy emphasis on increasing vaccine introduction and uptake in low-income countries.

\section{High Priority Research to Advance Prevention of HPV- Associated Cancers}

In addition to the four goals outlined in the Cancer Panel 2012-2013 report, the panel also suggested funding "high-priority" research to advance prevention of HPV-associated cancers. The panel hopes that the government would continue to fund HPV vaccine research that:

- Investigates more convenient dosing schedule for current vaccines. With hopes of producing evidence that HPV can be treated with fewer vaccine doses.

- Develops next-generation vaccines that provide better protection and/or are easier to store and administer. This would allow for changes in vaccine formulation that would increase coverage of HPV types and would allow for easier storage and management.

- Explain the natural history of or pharyngeal HPV infections. Knowledge of the pathology of or pharyngeal HPV remains to be conclusive. Research would allow for the investigation and introduction of biomarkers that aid in the recognition and diagnosis of this malignancy, which can possibly be eradicated through vaccination.

- Develop more effective ways to communicate about HPVassociated diseases and HPV vaccines through mobile health interventions. Specific strategies should be tested among different populations in accordance with sociocultural factors in order to determine the best way to convey messages regarding the HPV vaccination series.

- Determine how best to integrate HPV vaccination with cervical cancer screening. This is of particular importance because studies show that African-American females are not being screened for cervical cancer, which may account for the high incidence and mortality rates in this population.

\section{Discussion}

The Human Papillomavirus vaccination is a novel approach to combat the incidence of HPV and its associated health outcomes in both male and female populations. The panel's report investigates and addresses causes of low vaccine uptake not only in the U.S., but globally [22]. The low rates of uptake and completion of the HPV vaccination series in the United States may be restored by placing an emphasis on populations that HPV and cervical cancer disproportionally affect, for example, African-American females [23].

In the United States, the current cervical cancer mortality rate for Black women (BW) is almost twice that of Caucasian Women (CW) (4.3 per 100,000 (BW) vs. 2.2 per 100,000 (CW)). Previous researchers demonstrated that Black women experience inadequate access to preventive services or do not use these services for a variety of reasons, including but not limited to transportation issues, availability of insurance, level of income or education, fear and mistrust of the health care system [24]. Inadequate diagnostic and therapeutic care also contribute to racial differences in late-stage cervical cancer diagnoses. 
Citation: McGhee E, Harper H, Ume A, Baker M, Diarra C, et al. (2017) Elimination of Cancer Health Disparities through the Acceleration of HPV Vaccines and Vaccinations: A Simplified Version of the President's Cancer Panel Report on HPV Vaccinations. J Vaccines Vaccin 8: 361. doi: $10.4172 / 2157-7560.1000361$

Page 6 of 7

Some reports documented a lack of follow-up visits after a Pap test among black women, and in some cases, this occurred at a patient's medical home. Various reports cite challenges in the patient-provider relationship that impede screening and follow-up efforts, particularly in African-American female populations. With Pap smears being paramount in the diagnosis of cervical cancer, it is imperative that future research efforts focus on ways to merge cervical cancer screenings with HPV vaccination uptake [25]. An intervention should focus on providers to improve skills required to nurture and enhance physician-patient relationship. Another study investigated factors that correlated with parental awareness of HPV vaccines using data from parents of both male and female pre-adolescents and adolescents. The study reported that their data indicated that most U.S. parents $(62.6 \%)$ have heard of HPV vaccines. Multivariable results revealed that parents of children who were older, female, and insured were more likely to have heard of HPV vaccines. Parents who were female, white (nonHispanic), English speakers, born in the U.S., married, had higher levels of education and higher incomes were also more likely to be aware of HPV vaccines. This data heavily suggests that ensuring access to quality healthcare is necessary to awareness, initiation and completion of the HPV vaccination series. As for cost and access to such vaccines, programs such as Vaccines for Children (VFC) and Merck Vaccine Patient Assistance Program (MVPAP) are available to those that have no health insurance or cannot afford the vaccines $[8,26]$. It is essential to address the obstacles to the uptake of the vaccines and identify and utilize solutions to promote greater awareness and access to the vaccines regardless of cultural, educational or socioeconomic backgrounds. The vaccines show potential to greatly reduce, possibly eradicating the presence of HPV-related cancers, and should be readily available to everyone globally $[27,28]$.

\section{Conclusion}

Accelerating HPV vaccination uptake will require the help of parents, the nation's public health providers and other public health professionals in order to make this a high priority issue. There are 600,000 cases worldwide each year with an HPV infection that could have been prevented with the completion of the HPV vaccination series, therefore reflecting the great efforts to eradicate this disease in the future. The current vaccines; Cervarix, Gardasil, and Gardasil 9 have been scientifically proven to be effective in decreasing the amount of disparities found in underrepresented areas. With other countries achieving success in HPV vaccinations, it is proven that it can be done. Incorporating the FOUR main goals from the presidents cancer panel; reducing missed clinical opportunities to recommend and administer vaccines, increase parents, caregivers, and adolescents acceptance of HPV vaccines, maximize access to HPV vaccination services, and promoting global HPV vaccine uptake we are a step closer to eliminating Human papillomavirus which in turn will aid in eliminating cancer disparities.

\section{Acknowledgements}

We would like to acknowledge the President Cancer Panel Members for writing the original vaccine uptake report on HPV: Elimination of Cancer Health Disparities Through the Acceleration of HPV Vaccines and Vaccinations.

\section{Grant Support}

NIH/NIMHD U54MD007598; NIH/NCI U54CA143931; NIH/ NIMHD S21MD000103; Pink Pumpkin Patch Breast Cancer Grant; CDU Mission Maker Mini Grant.

\section{References}

1. Woodman CB, Collins SI, Young LS (2007) The natural history of cervical HPV infection: unresolved issues. Nat Rev Cancer 7: 11-22.

2. Freeman HP, Wingrove BK (2005) Excess cervical cancer mortality: a marker for low access to health care in poor communities. Rockville, MD: National Cancer Institute, Center to reduce cancer health disparities 5: 5282 .

3. Rimer B, Harper H, Witte O (2014) Accelerating HPV vaccine uptake: urgency for action to prevent cancer; a report to the President of the United States from the President's Cancer Panel. Bethesda, MD: National Cancer Institute.

4. Nakagawa M, Spencer HJ, Coleman HN, Greenfield WW (2013) Distribution of human papillomavirus (HPV) types and anti-HPV T-cell immune responses among different racial/ethnic groups in Central Arkansas. J Arkansas Medical Society 109: 160.

5. Mighty KK, Laimins LA (2014) The role of human papillomaviruses in oncogenesis. Recent Results Cancer Res 193: 135-148.

6. de Martel C, Ferlay J, Franceschi S, Vignat J, Bray F, et al. (2012) Global burden of cancers attributable to infections in 2008: a review and synthetic analysis. Lancet Oncol 13: 607-615.

7. Jit M, Brisson M, Laprise JF, Choi YH (2015) Comparison of two dose and three dose human papillomavirus vaccine schedules: cost effectiveness analysis based on transmission model. BMJ 350: g7584.

8. Control CfD, Prevention (2013) National and state vaccination coverage among adolescents aged 13-17 years-United States, 2012. MMWR Morbidity and mortality weekly report 62: 685 .

9. Joura EA, Giuliano AR, Iversen OE, Bouchard C, Mao C, et al. (2015) A9valent HPV vaccine against infection and intraepithelial neoplasia in women. New England J Medicine 372: 711-23.

10. Giuliano AR, Anic G, Nyitray AG (2010) Epidemiology and pathology of HPV disease in males. Gynecol Oncol 117: S15-19.

11. Smith GD, Travis L (2011) Getting to know human papillomavirus (HPV) and the HPV vaccines. J Am Osteopath Assoc 111: S29-34.

12. Steinbrook R (2006) The potential of human papillomavirus vaccines. $\mathrm{N}$ Engl J Med 354: 1109-1112.

13. Moss JL, Reiter PL, Brewer NT (2015) Correlates of human papillomavirus (HPV) vaccine coverage: A state-level analysis. Sexually transmitted diseases 42: 71.

14. Scarinci IC, Litton AG, Garcés-Palacio IC, Partridge EE, Castle PE (2013) Acceptability and usability of self-collected sampling for HPV testing among African-American women living in the Mississippi Delta. Women's Health Issues 23: e123-e30.

15. Holman DM, Benard V, Roland KB, Watson M, Liddon N, et al., (2014) Barriers to human papillomavirus vaccination among US adolescents: a systematic review of the literature. JAMA pediatrics 168: 76-82.

16. Reiter PL, McRee AL, Pepper JK, Chantala K, Brewer NT (2012) Improving human papillomavirus vaccine delivery: a national study of parents and their adolescent sons. J Adolescent Health 51: 32-37.

17. Sledge JA (2015) The male factor: human papillomavirus (HPV) and HPV4 vaccine acceptance among African American young men. Journal of community health. 40: 834-842.

18. Campbell CMP, Kreimer AR, Lin HY, Fulp W, O'Keefe MT, et al., (2015) Long-term persistence of oral human papillomavirus type 16: the HPV Infection in Men (HIM) study. Cancer Prevention Research 8: 190-196.

19. Lu Pj, Williams WW, Li J, Dorell C, Yankey D, et al. (2013) Human papillomavirus vaccine initiation and awareness: US young men in the 2010 National Health Interview Survey. Ame J Preventive Medicine 44: 330-338. 
Citation: McGhee E, Harper H, Ume A, Baker M, Diarra C, et al. (2017) Elimination of Cancer Health Disparities through the Acceleration of HPV Vaccines and Vaccinations: A Simplified Version of the President's Cancer Panel Report on HPV Vaccinations. J Vaccines Vaccin 8: 361. doi:10.4172/2157-7560.1000361

Page 7 of 7

20. Perkins RB, Clark JA (2012) Providers' attitudes toward human papillomavirus vaccination in young men: challenges for implementation of 2011 recommendations. American J Men's Health 6: 320-323.

21. Pascual A, Pariente M, Godinez J, Sánchez-Prieto R, Atienzar M, et al. (2007) High prevalence of human papillomavirus 16 in penile carcinoma Histology and histopathology 22: 177-184.

22. Demasio KA (2003) The complexity of finding solutions to reducing racial/ethnic disparities in health care outcomes. Commentary on" A community approach to addressing excess breast and cervical cancer mortality among women of African descent in Boston". Public Health Reports 118: 348 .

23. Smith ER, Adams SA, Das IP, Bottai M, Fulton J, et al. (2008) Breast cancer survival among economically disadvantaged women: the influences of delayed diagnosis and treatment on mortality. Cancer Epidemiology and Prevention Biomarkers. 17: 2882-2890.

24. Kennedy S, Osgood R, Rosenbloom L, Feinglass J, Simon M (2011) Knowledge of human papillomavirus among publicly and privately insured women. J Midwifery \& Women's Health 56: 481-487.
25. Ashing-Giwa KT, Gonzalez P, Lim JW, Chung C, Paz B, et al. (2010) Diagnostic and therapeutic delays among a multiethnic sample of breast and cervical cancer survivors. Cancer 116: 3195-3204.

26. Stokley S, Cohn A, Jain N, McCauley MM (2011) Compliance with recommendations and opportunities for vaccination at ages 11 to 12 years: evaluation of the 2009 National Immunization Survey-Teen. Archives of Pediatrics \& Adolescent Medicine 165: 813-818.

27. Tariq S, Bhakta S, Grimes A, Stevens A (2009) Attitudes of Arkansas' primary care physicians toward the HPV vaccine. J Ark Med Soc 106: 113-117.

28. Barry J, Breen N (2005) The importance of place of residence in predicting late-stage diagnosis of breast or cervical cancer. Health Place 11: 15-29. 